\title{
AWARENESS AMONG YOUTH ABOUT HIV \& TB- A COMPARATIVE STUDY
}

\author{
Allena Nishant ${ }^{1}$, Pradeep Kumar Palakonda ${ }^{2}$, MV Shanti Annapurna ${ }^{3}$ \\ ${ }_{1}^{1}$ Student, MBBS, Department of Community Medicine, MIMS, Vizianagaram, Andhra Pradesh. \\ ${ }^{2}$ Assistant Professor, Department of ENT, Great Eastern Medical School, Ragolu, Srikakulam. \\ ${ }^{3}$ Postgraduate Student, Department of Pulmonary Medicine, Andhra Medical College, Visakhapatnam.
}

\section{ABSTRACT}

\section{BACKGROUND}

India has a high burden of diseases such as Tuberculosis (TB), HIV/AIDS and also HIV-TB co-infection. As children and youth are a valuable resource for the future of a country, this study was conducted to assess the awareness among youth about HIV and TB and to compare awareness about TB with that of HIV.

\section{MATERIALS AND METHODS}

It is a cross-sectional observational study conducted on 500 students studying in a degree college in Visakhapatnam. All of them were in the age group of 18-20 years. A printed questionnaire with multiple choice answers was handed over to them and they were asked to choose the appropriate answer.

\section{RESULTS}

The mean of awareness about HIV was 65.57 but that of tuberculosis was only 48.14. Awareness of tuberculosis was found to be significantly lower when compared to that of $\operatorname{HIV}(\mathrm{P}<0.0001)$.

\section{CONCLUSION}

Awareness about tuberculosis is much less compared to that of HIV/AIDS. Most of the students read about these diseases in their books as a part of their curriculum, but they were less exposed to other awareness programmes conducted by the government. Awareness among youth about cough etiquette and tuberculosis has to be increased immediately by all possible means, so that they can protect themselves and future generations.

\section{KEYWORDS}

TB, Tuberculosis, HIV, AIDS, Awareness, Youth.

HOW TO CITE THIS ARTICLE: Nishant A, Palakonda PK, Annapurna MVS. Awareness among youth about HIV \& TB- A comparative study. J. Evolution Med. Dent. Sci. 2017;6(49):3768-3771, DOI: 10.14260/Jemds/2017/814

\section{BACKGROUND}

India has the highest burden of tuberculosis (TB) in the world, accounting for approximately one-fifth of the global incidence - an estimated two million cases annually.[1] India alone accounts for more than $25 \%$ of the world's incident cases.[2] Under Revised National Tuberculosis Control Programme, through a consistent communication, a lot of awareness has been created about TB - about its cause, symptoms, and cure, as well as various misconceptions and stigmas attached to it. Studies on awareness of TB and treatment seeking behaviour have been carried out in various parts of India on various subgroups. ${ }^{[3-5]}$

Acquired Immune Deficiency Syndrome (AIDS) caused by Human Immunodeficiency Virus (HIV) is posing a serious challenge to the conceptual foundations and the practice of development planning Worldwide. Nearly half of the new HIV infections are occurring in young people.

Financial or Other, Competing Interest: None.

Submission 18-04-2017, Peer Review 08-06-2017,

Acceptance 13-06-2017, Published 19-06-2017.

Corresponding Author:

Pradeep Kumar Palakonda,

\#12-5-4, Mahalaxmi Nagar Colony,

Behind Girl's High School,

Srikakulam-532001,

Andhra Pradesh, India.

E-mail: pradeeppalakonda@gmail.com

DOI: $10.14260 /$ jemds/2017/814

\section{(c) (1) ()요}

HIV/AIDS is retarding economic growth by destroying human capital by mainly affecting the young adults in the age group of 15-24 years who are in their most productive ages of life. At the state level, different organisations are actively working to spread awareness in schools, colleges and communities. The School Adolescent Education Programme and Integrated Rural AIDS Awareness Programme for rural people are two such programmes to create awareness of HIV/AIDS.

Persons infected by Tubercle bacilli have about a $10 \%$ chance of developing tuberculosis during the remainder of their lives. Thus, they have a less than $0.5 \%$ chance of developing overt disease annually, ${ }^{[6]}$ while $10 \%$ of persons infected by both TB and HIV develop tuberculosis disease annually.[7] The implication of HIV infection is that it activates dormant tuberculosis to rapid disease progression of tuberculosis and death. ${ }^{[8]} \mathrm{In}$ fact, tuberculosis is now the most common opportunistic infection in patients from developing countries who die from AIDS.[6] Reports show that active tuberculosis increases the morbidity and fatality of HIVinfected person and about one-third die of tuberculosis.[9] The largest increase in tuberculosis has occurred in locations and demographic groups with the highest HIV prevalence, which suggests that the epidemic of HIV is at least partially responsible for the increase of tuberculosis.[10]

Programme managers and policy makers have often recommended that schools, colleges can act as the centre point for disseminating information and education. Hence, school education has been described as a 'social vaccine', and it can serve as a powerful preventive tool. As children and 
youth are a valuable resource for the future of a country, it is imperative that they be equipped with ample amount of information so as to protect themselves and their counterparts from falling prey to these diseases.

With this background, this study was conducted to assess the awareness among youth about HIV and TB, and to compare the awareness about Tuberculosis with that of HIV.

\section{MATERIALS AND METHODS}

It is a cross-sectional observational study conducted on 500 students studying in a degree college in Visakhapatnam. Sample size was calculated using Slovin's formula $(\mathrm{n}=\mathrm{N} /(1+\mathrm{Ne} 2)$, estimating $\mathrm{N}$ as $1,00,000$ degree college students in Visakhapatnam, at a confidence level of $95 \%$ and margin of error 0.05 , sample size ' $n$ ' $=398$. All of them were in the age group of $18-20$ years. Of them, 289 were boys and 211 were girls. Permission was taken from the Principal of the selected degree college in Visakhapatnam to conduct the study in their college. All the students were explained about the study, and all those who orally consented to participate were included in the study. A printed questionnaire about HIV and TB with multiple choice answers was handed over to them and they were asked to choose the appropriate answer. Questionnaire was in both English and Telugu.

\section{RESULTS}

All the data was entered and analysed using Microsoft excel software. Statistical analysis using t-test was carried out in GraphPad Prism software.

\begin{tabular}{|c|c|c|}
\hline Question & \multicolumn{2}{|c|}{$\begin{array}{c}\text { No. of students who answered } \\
\text { correctly out of 500 students }\end{array}$} \\
\hline $\begin{array}{c}\text { What is the cause of } \\
\text { disease? }\end{array}$ & $100(20 \%)$ & $65(13 \%)$ \\
\hline $\begin{array}{c}\text { What are the } \\
\text { symptoms? }\end{array}$ & $315(63 \%)$ & $335(67 \%)$ \\
\hline Is it contagious? & $350(70 \%)$ & $415(83 \%)$ \\
\hline How does it spread? & $350(70 \%)$ & $235(47 \%)$ \\
\hline $\begin{array}{c}\text { How can we prevent } \\
\text { disease? }\end{array}$ & $415(83 \%)$ & $250(50 \%)$ \\
\hline Can it be cured? & $365(73 \%)$ & $285(57 \%)$ \\
\hline $\begin{array}{c}\text { What is the duration } \\
\text { of treatment? }\end{array}$ & $400(80 \%)$ & $100(20 \%)$ \\
\hline Table 1. Awareness about HIV and TB among Youth \\
\hline
\end{tabular}

It was observed that $20 \%$ of the students knew that the cause of HIV was a microorganism while only $13 \%$ knew that cause of Tuberculosis was a microorganism. $63 \%$ knew the symptoms of HIV/AIDS and $67 \%$ knew the symptoms of Tuberculosis. $70 \%$ knew that HIV is contagious and $83 \%$ knew that Tuberculosis is contagious. $70 \%$ knew the mode of transmission of HIV and $83 \%$ knew how to prevent HIV transmission, but only $47 \%$ knew the mode of transmission of Tuberculosis and 50\% knew the measures to be followed to prevent transmission of Tuberculosis. Most of them thought that smoking is the cause of Tuberculosis and it spreads by eating and staying with tuberculosis patients. $73 \%$ knew that HIV/AIDS can be controlled by medications and $80 \%$ knew that treatment should be continued lifelong but only $57 \%$ knew that tuberculosis can be cured completely and only $20 \%$ knew that the duration of its treatment is a minimum of 6 months.

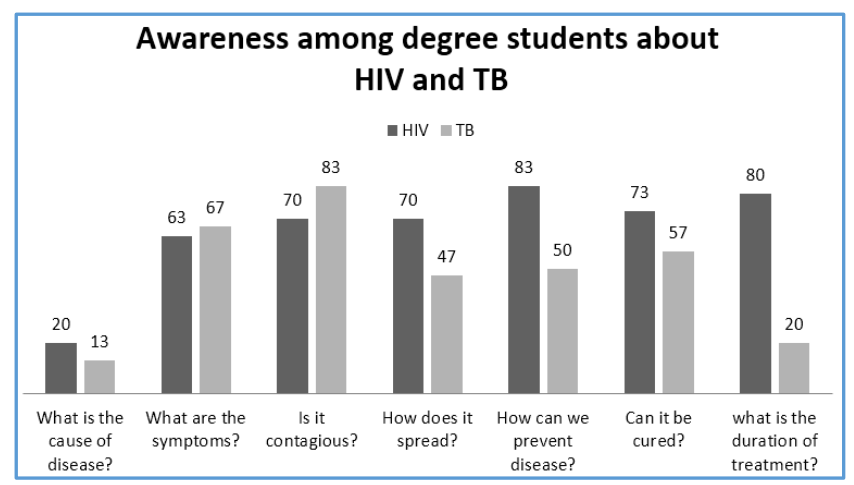

\begin{tabular}{|c|c|c|}
\hline & $\begin{array}{c}\text { Awareness about } \\
\text { HIV }\end{array}$ & $\begin{array}{c}\text { Awareness about } \\
\text { TB }\end{array}$ \\
\hline Mean & 65.57 & 48.14 \\
\hline Standard Deviation & 21.2 & 24.8 \\
\hline n (sample size) & 500 & 500 \\
\hline Table 2. Awareness about HIV is more than that of TB \\
\hline
\end{tabular}

The mean of awareness about HIV was 65.57 but that of tuberculosis was only 48.14. Awareness of tuberculosis was found to be significantly lower when compared to that of HIV $(\mathrm{P}<0.0001)$. Overall, we have observed that students had much less awareness about Tuberculosis than HIV/AIDS, though tuberculosis is easily transmitted than HIV and is almost equally dangerous - due to increase in the number of Multidrug Resistant-TB (MDR-TB) and Extremely Drug Resistant-TB (XDR-TB) cases.

Following responses were obtained from students when asked about the source of their knowledge about these diseases. $74 \%$ read about HIV in books and $10 \%$ heard it from their friends, $3 \%$ saw on Television, $13 \%$ from posters. $63 \%$ read about Tuberculosis in books, $23 \%$ heard about it from friends, $10 \%$ saw on Television and 3\% heard from health workers. So, our observation was that most of the students read about these diseases in their books as a part of their curriculum, but they were less exposed to other awareness programmes conducted by the government.

\section{SOURCE OF AWARENESS}

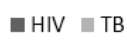

74

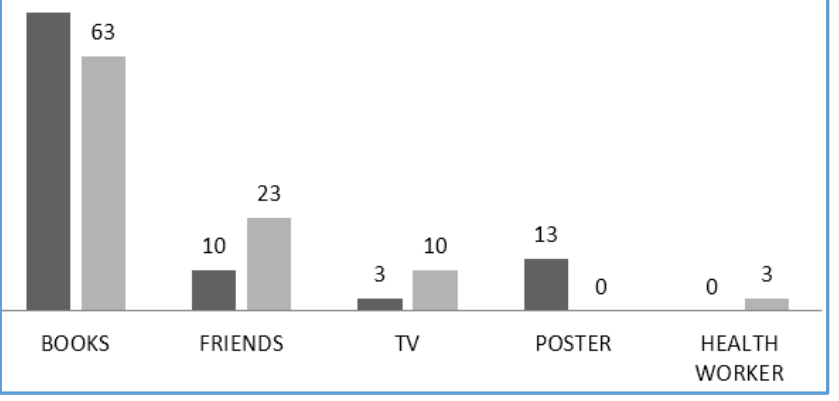

\section{DISCUSSION}

Our study subjects had better awareness about HIV/AIDS than tuberculosis. This is the first study done comparing the awareness about TB with that of HIV. The growing incidence 
of both these diseases despite national control programs, and a close relationship that has emerged between tuberculosis and HIV, is the motivation behind this study.

In a study(11) conducted about awareness of tuberculosis in an urban slum of Puducherry in 2013, $71 \%$ considered TB as a serious disease, $82 \%$ were aware that cough is a symptom of TB, $81 \%$ stated that TB can spread from one person to another, $65 \%$ were aware of spread by cough, $87 \%$ said that TB is curable and $42 \%$ were aware of the treatment duration of 6 months. Though our study was conducted among degree college students in an urban area, to our astonishment, awareness among students was less - only $67 \%$ knew the symptoms of TB, $83 \%$ knew that it was contagious but only $47 \%$ were aware of spread by cough and $57 \%$ knew that TB is curable but only $20 \%$ were aware of the duration of treatment.

In a study ${ }^{(12)}$ conducted in 2007 in rural areas of Gujarat, among young people aged 15 to 24 years with $86.58 \%$ literates, $61 \%$ had heard about HIV/AIDS, $92.42 \%$ knew that the disease was transmitted, $>80 \%$ of the participants among those who had heard about HIV/AIDS were aware of various preventive measures against its spread. The sources of information regarding HIV/AIDS were: friends- 77\%, television- $69 \%$, health workers $-18 \%$, newspapers - $12 \%$, radio- $9 \%$, magazines- $3 \%$ and wall slogans or billboards $7 \%$. Our study group was also in the same age group, and all were educated i.e. degree college students, but only $70 \%$ knew that HIV was contagious and $83 \%$ were aware of the preventive measures against its spread. The sources of information in our study were: $74 \%$ - books, $10 \%$ - friends, $3 \%$ - television and $13 \%$ - posters.

By comparing our study with the above studies, we observed that though our study group are students and are actually more educated than the previous study groups, they had less awareness about these diseases. The possible reason could be that the students are more into academic knowledge than general knowledge. Most of them might be pursuing education only for the sake of certification rather than to acquire knowledge applicable in life. We also observed that major source of their information about the diseases were books, unlike the villagers in other study whose major sources were friends and television.

Twenty-five hundred years ago Hippocrates described Tuberculosis as the most widespread disease of his time and he claimed it almost always fatal. At the height of the Roman Empire, his successor Galen saw treatment of the disease to be so often useless that he allegedly warned colleagues against visiting patients in late stages of the disease, because their inevitable death might damage the reputation of the physician.(13)

For many centuries, tuberculosis has been the most important of human infections, in its global prevalence, devastating morbidity and massive mortality. It has been called the 'white plague' and 'the captain of all the men of death'. It was only in the last 150 years that a public health response began to unfold. The actual infective agent was not discovered until 1882; Robert Koch would win a Nobel Prize for his work.(14) Before the turn of the century, diagnosis incorporated then-cutting edge technology, the X-ray. The BCG vaccine while still of uncertain efficacy, offered some protection to children from the 1920s onward. Thomas McKeown et al (1975) concluded that public health played a negligible role in the historical decrease in disease mortality, including from $\mathrm{TB}$, emphasising that increased standards of living, including better nutrition, were the deciding factors.(15) Indeed, the link between poverty and TB had been recognised by the medical profession for some time; Sir William Osler, sometimes considered the Father of Modern Medicine, described TB as "A Social Disease with Medical Aspects." The turning point came in the 1940s with the discovery of the first drugs effective against TB, an achievement worthy of another Nobel Prize.(14) Prior to such treatment, close to half of all patients died within five years and with treatment, most patients were cured. As more drugs were discovered, it was soon possible to close Sanatoria, and treat patients entirely on an outpatient basis.(16)

TB was also the first context in which health economics and population impact of disease were studied.(17) Tools were developed so rapidly, and proved so effective, that by the 1960s, the WHO was targeting the complete elimination of TB worldwide. Yet by the time HIV appeared, TB was no longer high on the public health agenda.

HIV is thought to have originated in non-human primates in sub-Saharan Africa and was transferred to humans late in the 19th or early in the 20th century.(18-20) The earliest welldocumented case of Human Immunodeficiency Virus in human dates back to 1959(21). The emergence and pandemic spread of the acquired immunodeficiency syndrome (AIDS) have posed the greatest challenge to public health in modern times. The first indication of this new syndrome came in the summer of 1981, from USA.(22) The International Committee on Virus Nomenclature in 1986 decided on the generic name human immunodeficiency virus (HIV) for these viruses.

Since then the HIV/AIDS pandemic has greatly contributed to the continuing threat of TB. Not only does HIV infection reactivate a latent tuberculosis infection, but it also makes the disease more serious and renders treatment ineffective. Tuberculosis in turn may hasten the development of HIV infection into active disease. So serious is the global threat of tuberculosis combined with multidrug resistance and concomitant HIV infection that the World Health Organization in 1993 took the unprecedented step of declaring this disease a global emergency.

It is a matter of grief that age old diseases are still persisting and also increasing in prevalence along with new diseases, but our youth still lack necessary awareness about these life-threatening diseases. Increasing awareness among people, especially youth will surely help in controlling both the diseases.

\section{CONCLUSION}

Awareness about Tuberculosis is much less compared to that of HIV/AIDS, though TB spreads easily by simple cough and MDR-TB \& XDR-TB are almost equally dangerous as HIV/AIDS. Most of the students read about these diseases in their books as a part of their curriculum, but they were less exposed to other awareness programmes conducted by the government. Awareness among youth about cough etiquette and tuberculosis has to be increased immediately by all possible means like showing in movie theatres, organising health education in colleges by inviting specialists, conducting essay writing, elocution, painting competitions on World health day (April $7^{\text {th }}$ ), World TB day (March 24th), 
World AIDS day (December 1st), etc., so that they can protect themselves and future generations.

\section{ACKNOWLEDGEMENTS}

We are very grateful to the Staff of Dr. Lankapalli Bullayya College, Visakhapatnam, for permitting us and helping us to conduct this study in their college. We also thank all the students who enthusiastically participated in this study.

\section{Abbreviations \\ HIV - Human Immunodeficiency Virus. \\ AIDS - Acquired Immune Deficiency Syndrome. \\ TB - Tuberculosis.}

\section{REFERENCES}

[1] Central TB division, directorate general of health services. New Delhi: Ministry of Health and Family Welfare, Nirman Bhawan. TB India. RNTCP Annual Report 2011:P 1.

[2] WHO report 2011. Geneva: World Health Organization 2011. Global tuberculosis control.

[3] Malhotra R, Taneja DK, Dhingra VK, et al. Awareness regarding tuberculosis in a rural population of Delhi. Indian J Community Med 2002;27(2):62-8.

[4] Fochsen G, Deshpande K, Diwan V, et al. Health care seeking among individuals with cough and tuberculosis: a population-based study from rural India. Int J Tuberc Lung Dis 2006;10(9):995-1000.

[5] Sharma N, Malhotra R, Taneja DK, et al. Awareness and perception about tuberculosis in the general population of Delhi. Asia Pac J Public Health 2007;19(2):10-5.

[6] Grange JM. Tuberculosis. In: Husler WJ, Sussman M, (eds). Topley and Wilson's microbiology and microbial infections. 9th edn. Vol: 3 London: Arnold 1998:391417.

[7] Enarson DA, Rieder HL, Arnadottir T, et al. Management of tuberculosis, a guide for low income countries. $5^{\text {th }}$ edn. Paris. International union against tuberculosis and lung disease (IUATLD) Tuberculosis and HIV 2000:10-53.

[8] Escott S, Nsuteby E, Walley J, et al. Management of TB in countries with high HIV prevalence. Afr Health 2001;23:12-5.

[9] DeCock KM, Soro B, Coulibaly IM, et al. Tuberculosis and HIV infection is sub-Sahara Africa. JAMA 1992;268(12):1581-7.

[10] Shafer RW. Tuberculosis. In: Broder S, Merigan TC, Bolognesi D (eds). Textbook of AIDS medicine. $2^{\text {nd }}$ edn. Baltimore: Williams and Wilkins (Publisher) 1994:259-82.
[11] Chinnakali P, Ramakrishnan J, Vasudevan K, et al. Level of awareness about tuberculosis in urban slums: Implications for advocacy and communication strategy planning in the national program. Lung India 2013;30(2):139-42.

[12] Yadav SB, Makwana NR, Vadera BN, et al. Awareness of HIV/AIDS among rural youth in India: a community based cross-sectional study. J Infect Dev Ctries 2011;5(10):711-6.

[13] Kim JY, Shakow A, Mate K, et al. Limited good and limited vision: multidrug-resistant tuberculosis and global health policy. Social Science \& Medicine 2005;61(4):847-59.

[14] The Nobel Prize in Physiology or Medicine 1905. Nobelprize.org 1905. http://www.nobelprize.org/nobel_prizes/.

[15] McKeown T, Record RG, Turner RD. An interpretation of the decline of mortality in England and Wales during the twentieth century. Population Studies 1975;29(3):391-422.

[16] Lee R. Time bomb-the global epidemic of multi-drugresistant tuberculosis. New York: McGraw-Hill 2003:17.

[17] Montaner JSG, Shillington A, Montaner LJG. HIV/AIDS treatment: lessons from the tuberculosis experience. Drug Resistance Updates 1998;1(3):157-60.

[18] Korber B, Muldoon M, Theiler J, et al. Timing the ancestor of the HIV-1 pandemic strains. Science 2000;288(5472):1789-96.

[19] Salemi M, Strimmer K, Hall WW, et al. Dating the common ancestor of SIVcpz and HIV-1 group $\mathrm{M}$ and the origin of HIV-1 subtypes by using a new method to uncover clock-like molecular evolution. The FASEB Journal 2000;15(2):276-8.

[20] Worobey M, Gemmel M, Teuwen DE, et al. Direct evidence of extensive diversity of HIV-1 in Kinshasa by 1960. Nature 2008;455(7213):661-4.

[21] Zhu T, Korber BT, Nahmias AJ, et al. An African HIV-1 sequence from 1959 and implications for the origin of the epidemic. Nature 1998;391(6667):594-7.

[22] Centers for Disease Control (CDC). A cluster of Kaposi's sarcoma and pneumocystis carinii pneumonia among homosexual male residents of Los Angeles and orange counties, California. MMWR Morbidity Mortality Weekly Report 1982;31(23): 305-7. 